\title{
Perancangan dan Analisa Sistem Kemudi Narrow Tilting Vehicle dengan Variasi Trackwidth dan Panjang Suspensi Arm
}

\author{
Idestrian Adzanta dan Unggul Wasiwitono \\ Jurusan Teknik Mesin, Fakultas Teknologi Industri, Institut Teknologi Sepuluh Nopember (ITS) \\ Jl. Arief Rahman Hakim, Surabaya 60111 Indonesia \\ e-mail: unggul@me.its.ac.id
}

\begin{abstract}
Abstrak - Seiring bertambahnya jumlah penduduk di suatu kota menyebabkan peningkatan pada jumlah kendaraan. Hal ini menyebabkan kepadatan lalu lintas yang menjadi masalah besar bagi penduduknya. Saat terjadi kemacetan, pergerakan menjadi terbatas khususnya pada mobil yang memiliki dimensi yang lebih lebar dibandingkan motor. Salah satu solusi untuk kondisi tersebut adalah dengan membuat desain kendaraan yang kecil, aman, dan irit bahan bakar yaitu dengan membuat kendaraan narrow tilting vehicle. Langkah awal yang dilakukan dalam proses perancangan sistem kemudi adalah membuat rancangan 3D sistem kemudi pada software. Pendekatan yang digunakan pada perancangan ini adalah melakukan simulasi kinematika dari sistem kemudi dengan variasi trackwidth sebesar $800 \mathrm{~mm}, 1000$ mm dan $1200 \mathrm{~mm}$. Selain itu variasi yang diberikan berupa panjang knuckle dan panjang hub steering untuk mengetahui pengaruhnya terhadap sudut belok menurut prinsip Ackerman. Kemudian dari masing-masing trackwidth akan dianalisa sudut camber yang dihasilkan dengan variasi panjang upper arm agar kendaraan tetap aman dan nyaman. Pada tugas ahkir ini hasil analisa yang didapatkan adalah konfigurasi trackwidth yang sesuai dengan prinsip belok Ackerman dicapai pada trackwidth $1000 \mathrm{~mm}$ dengan panjang knuckle $134 \mathrm{~mm}$ dan panjang hub steering 139,64 mm. Rancangan tersebut menghasilkan sudut belok roda dalam( $\delta i) 38^{\circ}$ dan sudut belok roda luar( $\delta o$ ) sebesar 27. Untuk variasi panjang upper arm pada trackwidth $1000 \mathrm{~mm}$ digunakan upper arm dengan panjang 457,5 $\mathrm{mm}$ yang menghasilkan sudut camber $\pm 0,6$.
\end{abstract}

Kata Kunci-Sistem kemudi, narrow three vehicle, kinematika suspensi, prinsip Ackerman, sudut camber.

\section{PENDAHULUAN}

$\mathrm{D}$ EWASA ini seiring dengan bertambahnya jumlah penduduk di suatu kota, menyebabkan peningkatan pada jumlah kendaraan. Dengan meningkatnya jumlah kendaraan hingga 5\% per tahun di Indonesia menyebabkan kepadatan lalu lintas yang menjadi masalah besar bagi penduduknya. Hal ini membuat tantangan baru bagi perusahaan industri otomotif untuk tidak hanya membuat kendaraan yang dapat dikemudikan, namun dapat membantu memecahkan permasalahan ini. Salah satu pemecahan untuk kondisi tersebut adalah dengan membuat desain kendaraan yang kecil, aman, dan irit bahan bakar. Sebagai contoh, di beberapa bagian negara seperti Cina, India, Thailand, dan Italia telah menggunakan jenis kendaraan electric three wheeler sebagai transportasi publik.

Kendaraan beroda tiga dianggap memiliki keunggulan yang merupakan kombinasi antara kendaraan roda dua dan roda empat. Konfigurasi kendaraan roda tiga sendiri ada dua macam yaitu konfigurasi Delta dengan satu roda di depan dan dua roda di belakang dan konfigurasi Tadpole(reverse trike) dengan dua roda di depan dan satu roda di belakang. Setiap konfigurasi tersebut memiliki kelebihan dan kekurangan masing-masing. Kelebihan kendaraan roda tiga dengan konfigurasi reverse trike antara lain tidak adanya komponen differential, side shafts dan drive shaft membuat efisiensi transmisi menjadi lebih besar. Konfigurasi reverse trike memungkinkan desain rangka yang menyerupai tetesan air, sehingga dapat mengurangi gaya hambat angin (aerodynamic drag) [1]. Selain itu, rangka yang lebih sederhana membuat biaya pembuatan menjadi lebih murah, dan tingkat keamanan lebih besar dibandingkan kendaraan roda dua.

Selain dapat mengurangi polusi udara, kendaraan ini mempunyai rancang yang melindungi penumpangnya seperti mobil dan mampu bermanuver bebas seperti halnya sepeda motor. Namun, desain ini memiliki kelemahan akibat bentuknya yang ramping dan ringan yang menyebabkan kendaraan menjadi tidak stabil saat berbelok tajam. Beberapa metode dapat dilakukan seperti mengatur sudut camber pada ban dan metode tilting [2]. Metode tersebut dapat dilakukan sesuai kebutuhan dari kendaraan. Saat membutuhkan kendaraan dengan kemampuan belok yang baik dengan kecepatan tinggi dapat menggunakan metode tilting, dan jika membutuhkan kendaraan dalam perkotaan dapat menggunakan metode pengaturan sudut camber pada ban.

\section{METODOLOGI PENELITIAN}

Pada penelitian ini, prosedur penelitian dilakukan dengan empat tahap. Tahap pertama adalah studi literatur tentang 
pengembangan dan penelitian mengenai berbagai macam narrow tilting vehicle (NTV) yang sudah ada beserta mekanisme tilting dari kendaraan tersebut. Tahap kedua adalah menentukan konfigurasi dan spesifikasi awal dari tilting three wheel vehicle yang akan dirancang. Tahap ketiga adalah melakukan survei ketersediaan barang penunjang sistem kemudi di pasaran. Tahap keempat adalah melakukan rancangan sesuai desain dan melakukan simulasi gerakan dan analisa kinematika menggunakan software. Dimana rancangan sistem kemudi yang dihasilkan seperti pada gambar 1 .

Untuk acuan sudut camber dibatasi sudut sebesar $\pm 1^{\circ}$ [3]dan acuan pada sudut belok kendaraan mengikuti perumusan Ackerman [4] yaitu:

$$
\cot \left(\delta_{o}\right)-\cot \left(\delta_{i}\right)=\frac{w}{l}
$$

Dimana $\delta_{o}$ merupakan sudut belok luar roda, $\delta_{i}$ adalah sudut dalam roda, w adalah panjang trackwidth kendaraan dan 1 adalah panjang jarak antara sumbu roda depan dan belakang kendaraan, seperti pada gambar 2.

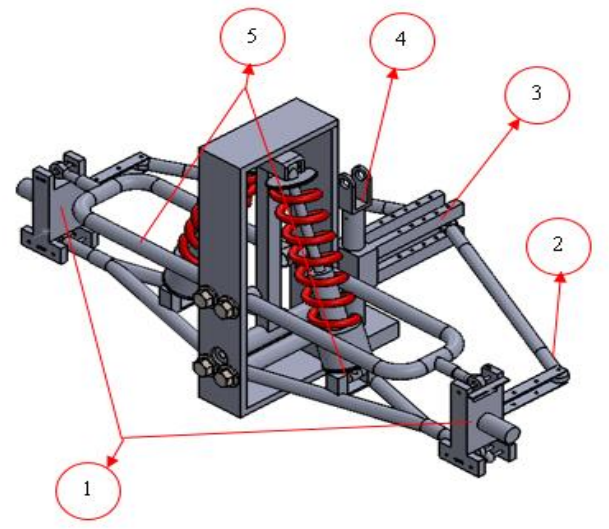

Gambar 1. Rancangan sistem kemudi NTV

Dimana nomor 1 adalah knuckle roda, nomor 2 adalah rod end steering, nomor 3 adalah hub steering, nomor 4 adalah joint steering, dan nomor 5 adalah upper arm.

\section{ANALISA DAN PEMBAHASAN}

\section{A. Rancangan Rangka dan Sistem Kemudi}

Pada rancangan sistem kemudi ini dilakukan pada batasan trackwidth sebesar $800 \mathrm{~mm}, 1000 \mathrm{~mm}$, dan $1200 \mathrm{~mm}$. Dimana rancangan narrow tilting vehicle pada penelitian ini menggunakan konfigurasi reverse trike yang dapat menampung dua penumpang dengan posisi duduk depan belakang, seperti pada gambar 2. Selain itu, dilakukan variasi terhadap panjang knuckle sebesar $60 \mathrm{~mm}$ hingga $134 \mathrm{~mm}$ dan panjang hub steering sebesar 59,64 mm hingga 139,64 mm. Untuk contoh variasi terhadap knuckle dan hub steering dapat dilihat pada gambar 3 .
Tabel 1. Spesifikasi rancangan NTV

\begin{tabular}{lc}
\hline \hline & Dimensi(mm) \\
\hline Panjang & 2211 \\
Lebar & 825 \\
Tinggi & 1580 \\
Wheel base (L) & 1811 \\
& Roda \\
Jumlah & 3 \\
Jari-jari roda & 16 inch \\
\hline \hline
\end{tabular}

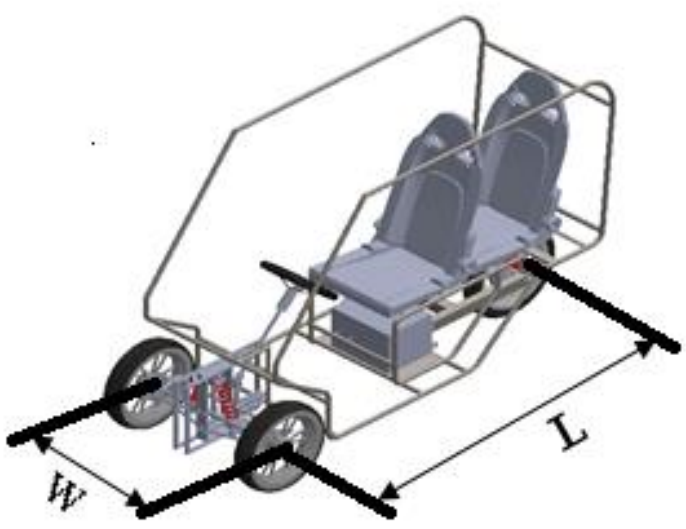

Gambar 2. Layout narrow tilting vehicle

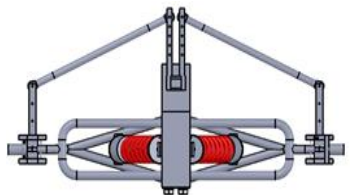

(a)

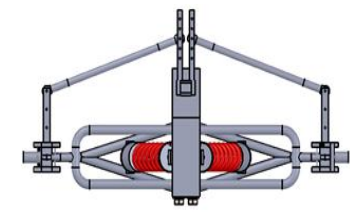

(b)

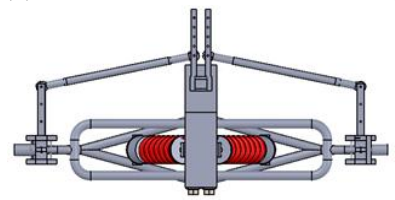

(c)

Gambar 3. Contoh gambar tampak atas sistem kemudi dengan variasi panjang hub steering (a) panjang 139,64 mm, (b) panjang 99,64 mm, (c) panjang 59,64 $\mathrm{mm}$

\section{B. Pengaruh Panjang Hub Steering terhadap Sudut Belok Kendaraan (Trackwidth $800 \mathrm{~mm}$ )}

Pada analisa sudut belok, kendaraan dianggap tidak mengalami tilting saat berbelok. Sehingga dapat memenuhi prinsip belok Ackerman. Variasi yang digunakan pada masingmasing trackwidth adalah dengan mengubah panjang hub steering. Pengambilan data simulasi dimulai dengan panjang 59,64 mm, 79,64 mm, 99,64 mm, 119,64 mm dan 139,64 mm. Selanjutnya, data simulasi dibandingkan dengan prinsip kondisi belok Ackerman. 


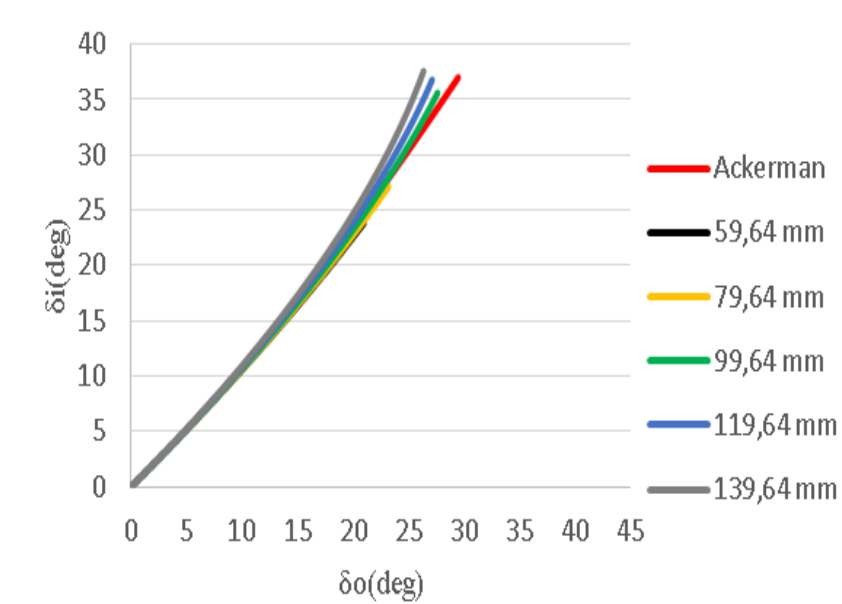

(a)

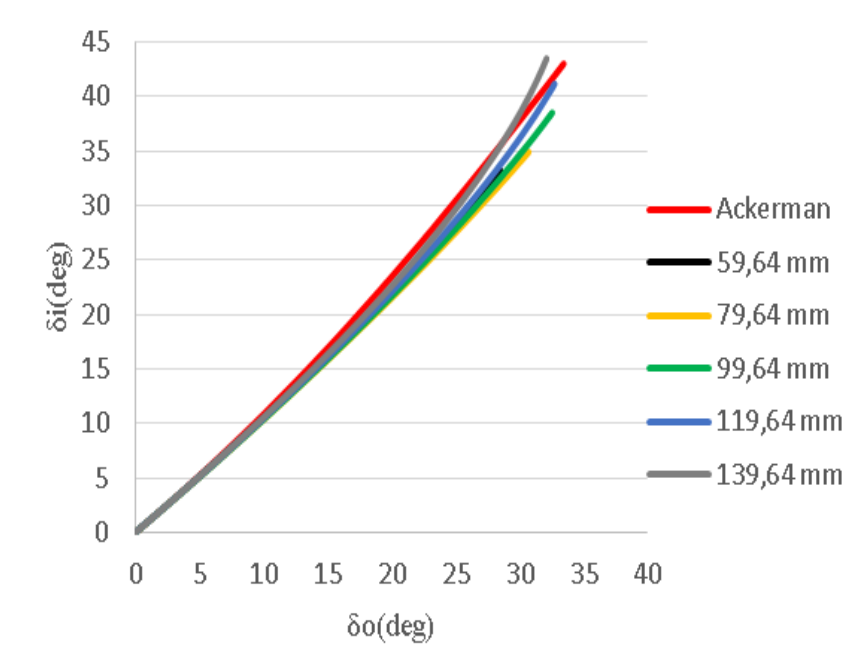

(b)

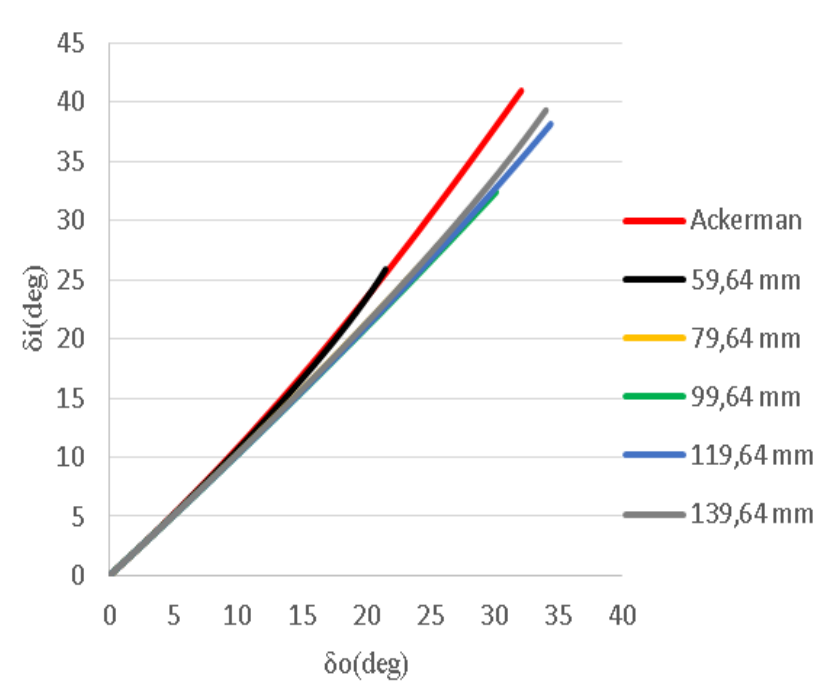

(c)

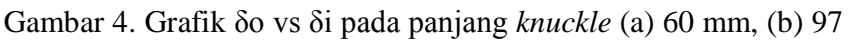
$\mathrm{mm},(\mathrm{c}) 134 \mathrm{~mm}$.

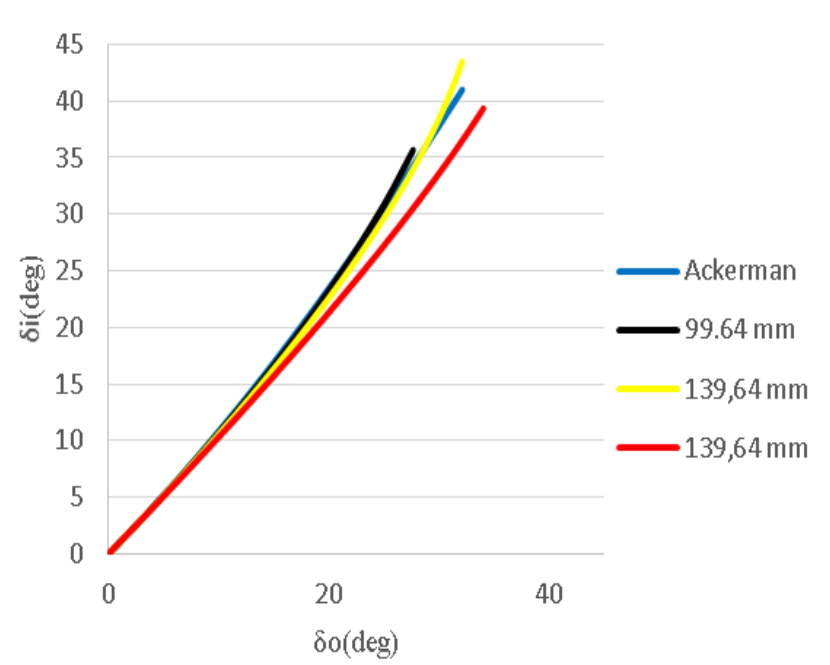

Gambar 5. Grafik $\delta$ o vs $\delta$ i tiap panjang knuckle yang paling mendekati prinsip Ackerman berturut-turut.

Dari gambar 4 diketahui bahwa perubahan panjang hub steering akan mempengaruhi tren grafik sudut belok yang dihasilkan. Perubahan panjang hub steering dan knuckle akan mempengaruhi rasio antara sudut belok roda dalam $(\delta i)$ dan sudut belok roda luar $(\delta o)$ dimana semakin panjang $h u b$ steering dan knuckle maka rasio antara $\delta i / \delta o$ akan semakin besar. Namun, pada gambar 4(c) untuk tren pada panjang $h u b$ $134 \mathrm{~mm}$ dan knuckle 59,64 mm terjadi penurunan rasio antara sudut belok roda dalam $(\delta i)$ dan sudut belok roda luar $(\delta o)$, dimana hal ini bisa terjadi akibat pengaruh dari rancangan sistem kemudi. Dengan variasi panjang hub steering didapatkan hasil sistem kemudi pada trackwidth $800 \mathrm{~mm}$ yang mendekati prinsip belok Ackerman yaitu dengan panjang knuckle 99,64 mm yang memiliki $\delta i$ sebesar $32^{\circ}$ dan $\delta o$ sebesar $26^{\circ}$ seperti pada gambar 5 .

\section{Pengaruh Panjang Hub Steering terhadap Sudut Belok Kendaraan (Trackwidth $1000 \mathrm{~mm}$ )}

Dari gambar 6 diketahui bahwa perubahan panjang hub steering akan mempengaruhi tren grafik sudut belok yang dihasilkan. Perubahan panjang hub steering dan knuckle akan mempengaruhi rasio antara sudut belok roda dalam $(\delta i)$ dan sudut belok roda luar $(\delta o)$ dimana semakin panjang $h u b$ steering dan knuckle maka rasio antara $\delta i / \delta o$ akan semakin besar. 


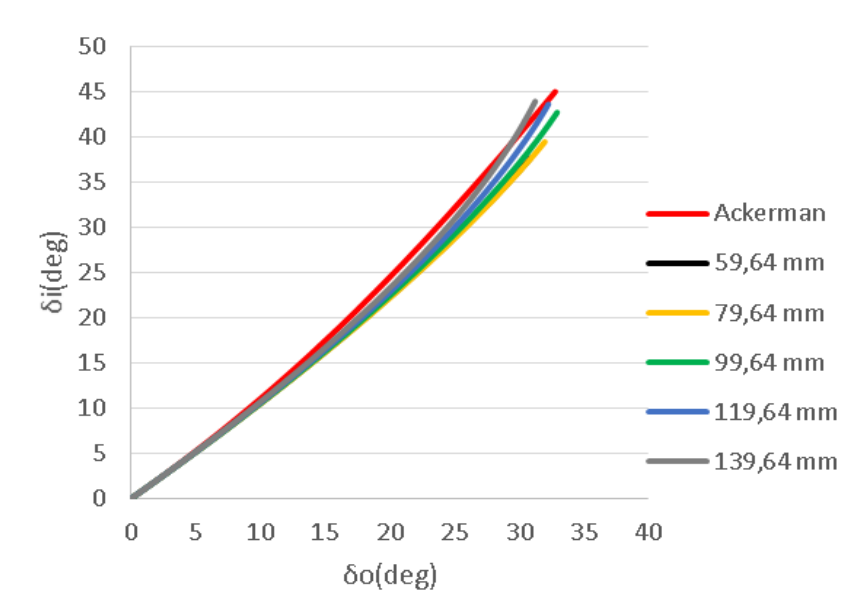

(a)

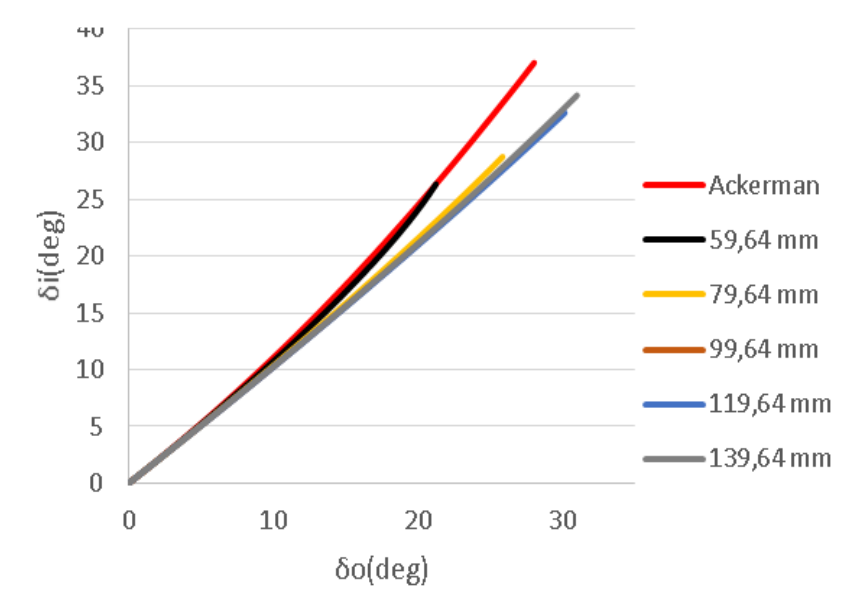

(b)

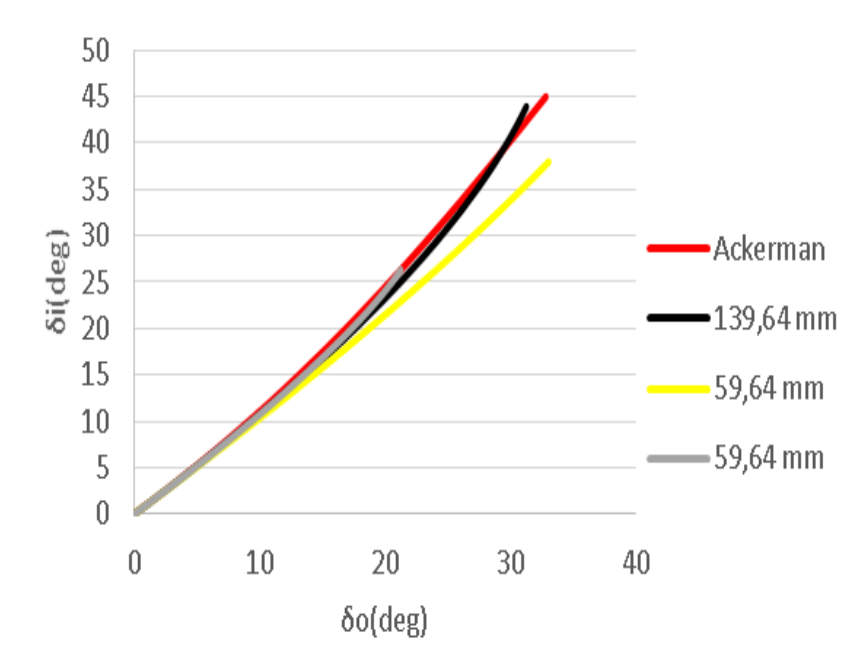

(c)

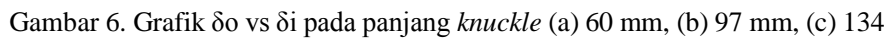
$\mathrm{mm}$.

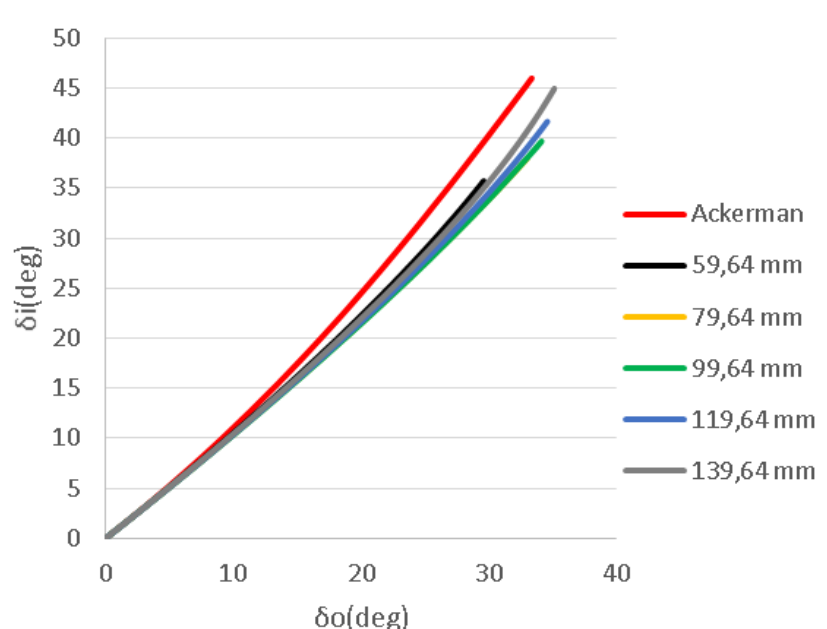

Gambar 7. Grafik $\delta$ o vs $\delta$ i tiap panjang knuckle yang paling mendekati prinsip Ackerman berturut-turut.

Namun, pada gambar 6(c) untuk tren grafik pada panjang hub $134 \mathrm{~mm}$ dan kemudi pada trackwidth $1000 \mathrm{~mm}$ yang mendekati prinsip belok Ackerman yaitu pada panjang knuckle $139,64 \mathrm{~mm}$ dengan nilai $\delta i$ sebesar $38^{\circ}$ dan $\delta o$ sebesar $27^{\circ}$ seperti pada gambar 7 .

\section{Pengaruh Panjang Hub Steering terhadap Sudut Belok \\ Kendaraan (Trackwidth $1200 \mathrm{~mm}$ )}

Dari gambar 8 diketahui bahwa perubahan panjang hub steering akan mempengaruhi tren grafik sudut belok yang dihasilkan. Perubahan panjang hub steering dan knuckle akan mempengaruhi rasio antara sudut belok roda dalam $(\delta i)$ dan sudut belok roda luar $(\delta o)$ dimana semakin panjang $h u b$ steering dan knuckle maka rasio antara $\delta i / \delta o$ akan semakin besar. Namun, pada gambar 8(c) untuk tren grafik pada panjang hub $134 \mathrm{~mm}$ dan knuckle 59,64 mm terjadi penurunan rasio antara sudut belok roda dalam $(\delta i)$ dan sudut belok roda luar $(\delta o)$, dimana hal ini bisa terjadi akibat pengaruh rancangan sistem kemudi.

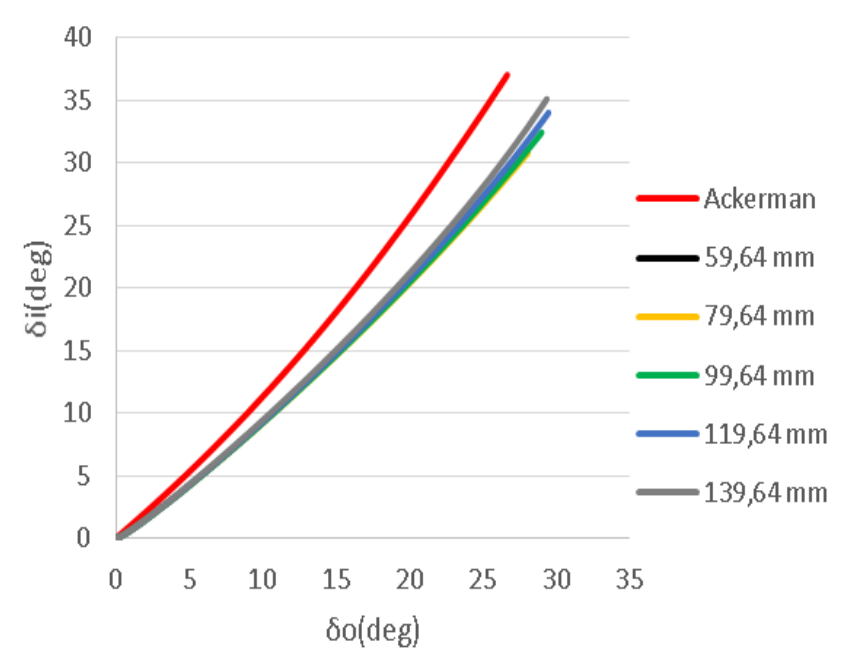

(a) 


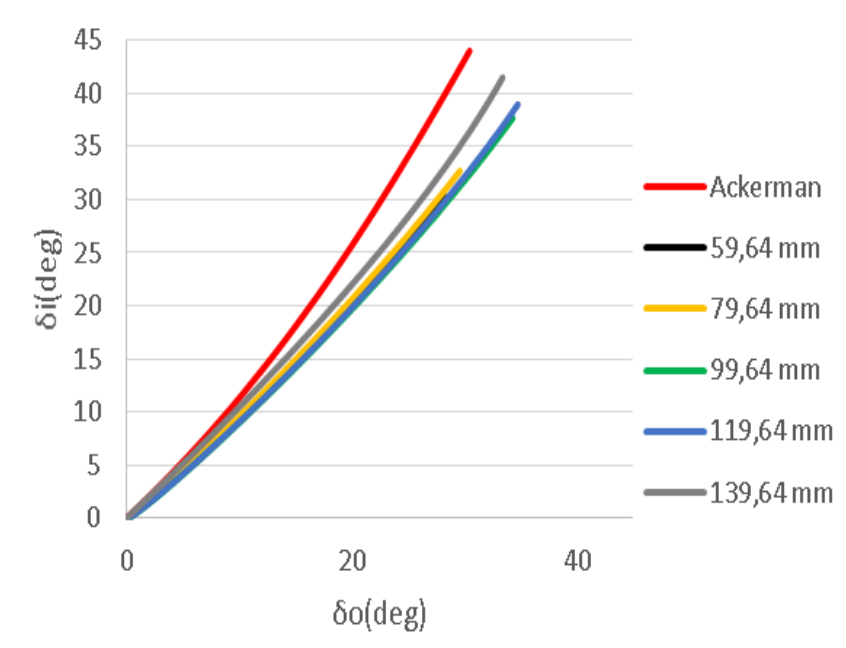

(b)

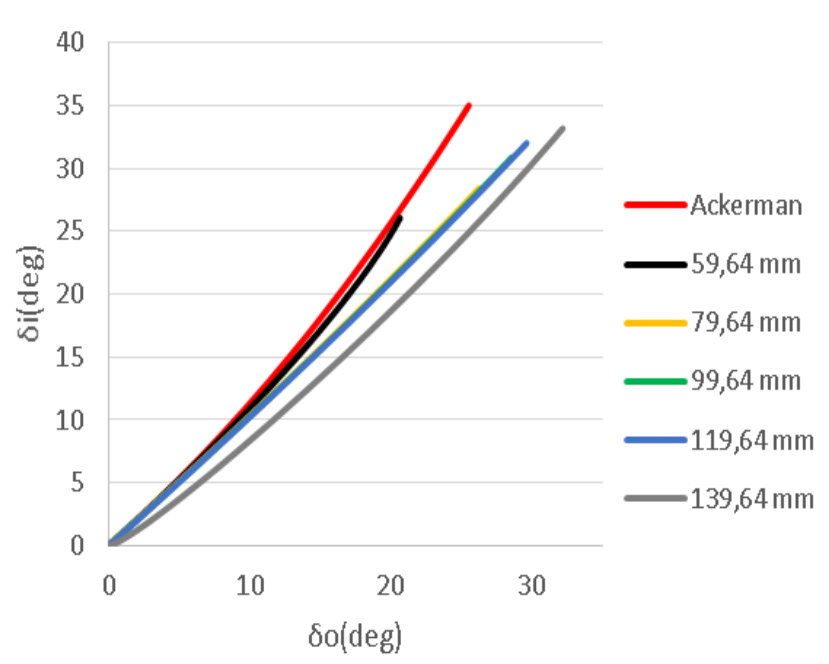

(c)

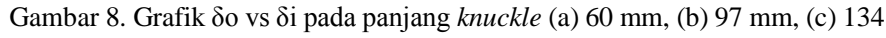
$\mathrm{mm}$

Dengan variasi panjang hub steering didapatkan hasil sistem kemudi pada trackwidth $1000 \mathrm{~mm}$ yang mendekati prinsip belok Ackerman yaitu pada panjang knuckle 59,64 mm $\delta i$ sebesar $26^{\circ}$ dan $\delta o$ sebesar $21^{\circ}$ seperti pada gambar 9 .

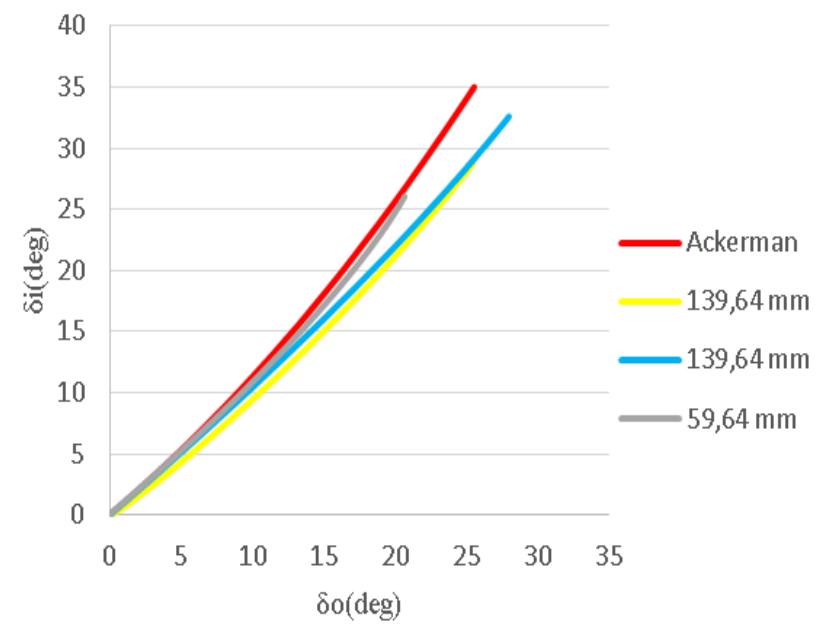

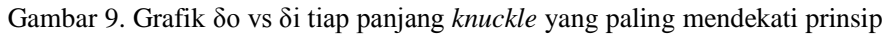
Ackerman berturut-turut.

\section{E. Pengaruh Panjang Upper Arm Terhadap Sudut Camber( $800 \mathrm{~mm})$}

Untuk menciptakan kenyamanan berkendara dilakukan analisa sudut camber pada roda. Pada penelitian ini dilakukan variasi terhadap panjang upper arm setiap trackwidth yaitu $300,5 \mathrm{~mm}, 320,5 \mathrm{~mm}, 325,5 \mathrm{~mm}, 330,5 \mathrm{~mm}$, dan 345,5 mm. Kemudian dari hasil simulasi sudut camber akan disesuaikan dengan teori sudut camber. Simulasi sudut camber akan disesuaikan dengan teori sudut camber. Dari gambar 10 terjadi penurunan tren grafik dari posisi wheel displacement negatif hingga posisi wheel displacement positif. Wheel displacement yang dimaksud disini adalah perubahan posisi roda terhadap sumbu vertikal roda [5]. Pengaruh perubahan panjang upper arm menyebabkan sudut camber yang terbentuk saat kondisi wheel displacement negatif menjadi lebih besar, namun saat kondisi wheel displacement positif menjadi lebih kecil.

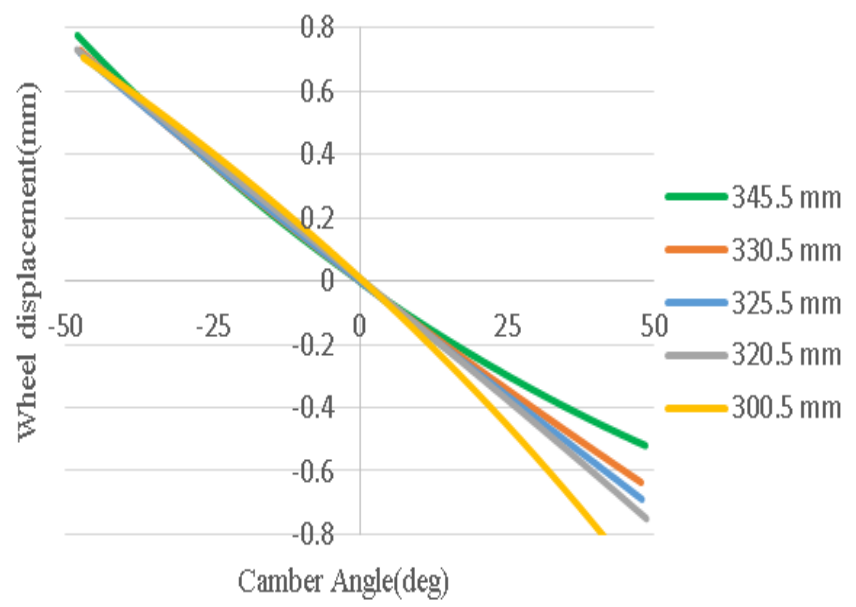

Gambar 10 Grafik camber angle vs wheel displacement pada trackwidth 800 $\mathrm{mm}$.

Hal ini sesuai dengan teori perubahan sudut camber dimana saat posisi wheel displacement negatif menghasilkan sudut camber positif dan wheel displacement positif menghasilkan sudut camber negatif. Selain itu, panjang upper arm mempengaruhi sudut camber yang terbentuk. Semakin panjang upper arm semakin kecil sudut camber yang dihasilkan, begitu juga sebaliknya. Untuk pemilihan sudut camber disarankan berada dalam kisaran sudut $\pm 1^{\circ}$. Dari gambar 10 dipilih upper arm dengan panjang $345,5 \mathrm{~mm}$ yang bertujuan agar kendaraan tetap stabil.

\section{F. Pengaruh Panjang Upper Arm Terhadap Sudut Camber ( $1000 \mathrm{~mm}$ )}

Untuk menciptakan kenyamanan berkendara dilakukan analisa sudut camber pada roda. Pada penelitian ini dilakukan variasi terhadap panjang upper arm setiap trackwidth yaitu 417,5 mm, 432,5 mm, 437,5 mm, 442,5 mm dan 457,5 mm. Kemudian dari hasil simulasi sudut camber akan disesuaikan dengan teori sudut camber. simulasi sudut camber akan disesuaikan dengan teori sudut camber. Dari gambar 11 terjadi penurunan tren grafik dari posisi wheel displacement negatif 
hingga posisi wheel displacement positif. Wheel displacement yang dimaksud disini adalah perubahan posisi roda terhadap sumbu vertikal roda. Pengaruh perubahan panjang upper arm menyebabkan sudut camber yang terbentuk saat kondisi wheel displacement negatif menjadi lebih besar, namun saat kondisi wheel displacement positif menjadi lebih kecil.

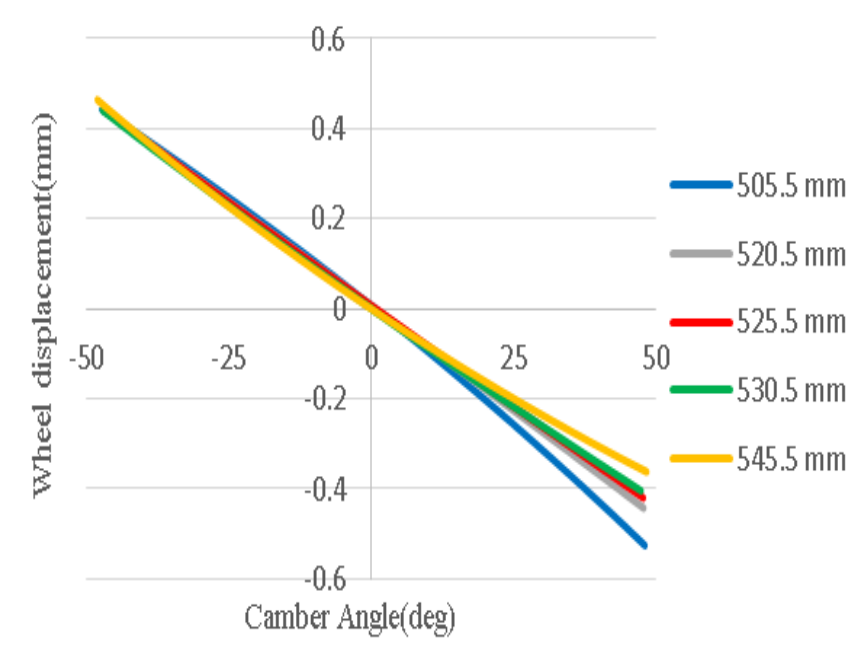

Gambar 11. Grafik camber angle vs wheel displacement pada trackwidth $1000 \mathrm{~mm}$.

Hal ini sesuai dengan teori perubahan sudut camber dimana saat posisi wheel displacement negatif menghasilkan sudut camber positif dan wheel displacement positif menghasilkan sudut camber negatif. Selain itu, panjang upper arm mempengaruhi sudut camber yang terbentuk. Semakin panjang upper arm semakin kecil sudut camber yang dihasilkan, begitu juga sebaliknya. Untuk pemilihan sudut camber disarankan berada dalam kisaran sudut $\pm 1^{\circ}$. Dari gambar 11 dipilih upper arm dengan panjang 457,5 mm yang bertujuan agar kendaraan tetap stabil.

\section{G. Pengaruh Panjang Upper Arm Terhadap Sudut Camber ( $1200 \mathrm{~mm}$ )}

Untuk menciptakan kenyamanan berkendara dilakukan analisa sudut camber pada roda. Pada penelitian ini dilakukan variasi terhadap panjang upper arm setiap trackwidth yaitu $505,5 \mathrm{~mm}, 520,5 \mathrm{~mm}, 525,5 \mathrm{~mm}, 530,5 \mathrm{~mm}$ dan $545,5 \mathrm{~mm}$. Kemudian dari hasil simulasi sudut camber akan disesuaikan dengan teori sudut camber. simulasi sudut camber akan disesuaikan dengan teori sudut camber. Dari gambar 12 terjadi penurunan tren grafik dari posisi wheel displacement negatif hingga posisi wheel displacement positif. Wheel displacement yang dimaksud disini adalah perubahan posisi roda terhadap sumbu vertikal roda. Pengaruh perubahan panjang upper arm menyebabkan sudut camber yang terbentuk saat kondisi wheel displacement negatif menjadi lebih besar, namun saat kondisi wheel displacement positif menjadi lebih kecil.

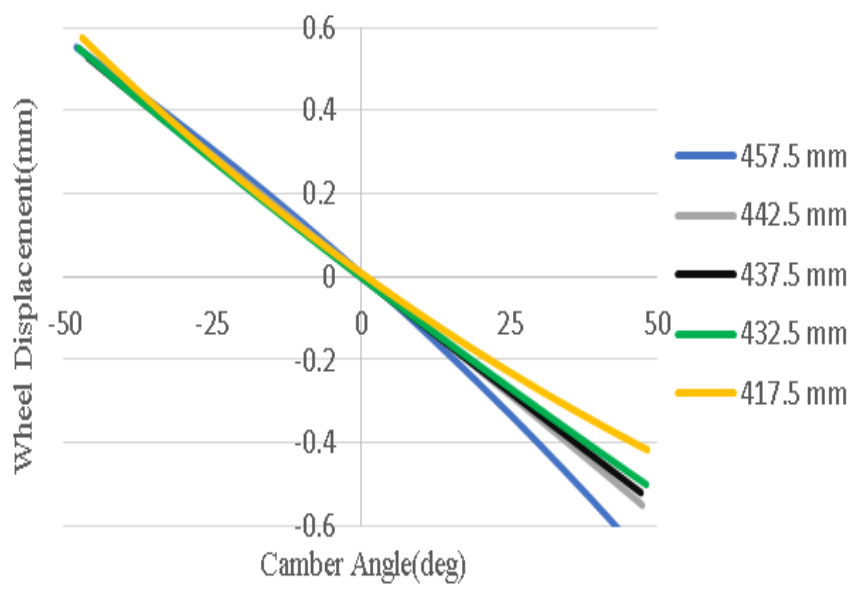

Gambar 12. Grafik camber angle vs wheel displacement pada trackwidth 1200 $\mathrm{mm}$.

Hal ini sesuai dengan teori perubahan sudut camber dimana saat posisi wheel displacement negatif menghasilkan sudut camber positif dan wheel displacement positif menghasilkan sudut camber negatif. Selain itu, panjang upper arm mempengaruhi sudut camber yang terbentuk. Semakin panjang upper arm semakin kecil sudut camber yang dihasilkan, begitu juga sebaliknya. Untuk pemilihan sudut camber disarankan berada dalam kisaran sudut $\pm 1^{\circ}$. Dari gambar 12 dipilih upper arm dengan panjang 545,5 mm yang bertujuan agar kendaraan tetap stabil.

\section{KESIMPULAN/RINGKASAN}

Hasil penelitian ini menunjukkan bahwa konfigurasi trackwidth yang sesuai dengan prinsip belok Ackerman dicapai pada trackwidth $1000 \mathrm{~mm}$ dengan panjang knuckle $134 \mathrm{~mm}$ dan panjang hub steering $139,64 \mathrm{~mm}$. Rancangan tersebut menghasilkan sudut belok roda dalam $(\delta i) 38^{\circ}$ dan sudut belok roda luar $(\delta o)$ sebesar 27 . Untuk variasi panjang upper arm pada trackwidth $1000 \mathrm{~mm}$ digunakan upper arm dengan panjang $457,5 \mathrm{~mm}$ yang menghasilkan sudut camber \pm 0.6 .

\section{DAFTAR PUSTAKA}

[1] Asimow, I.Morris. (1963). Introduction to Design. New Jersey: Prentice- Hall.

[2] Dixon, John C. (2009). Suspension Geometry and Computation. United Kingdom: J.Wiley.

[3] Milliken,F. William \& Milliken, L.Douglas.(1995). Race Car Vehicle Dynamics. Warrendale : SAE.

[4] Jazar, Reza N. (2009). Vehicle Dynamics : Theory and Applications. New York : Springer.

[5] S, -J. Park and J, -H. Sohn. (2011). Effects of Camber Angle Control of Front Suspension on Vehicle Dynamic Behaviours. Journal of Mechanical Science and Technology, 26, 307-313. 